\title{
Morphometric Measurements of Talus in South Keralites
}

\author{
Leena Ammini Bhaskaran¹, Latha Sreedhar Lekshmi Sreedhar ${ }^{2}$ \\ 1, 2 Department of Anatomy, Government Medical College, Thiruvananthapuram, Kerala, India.
}

\section{ABSTRACT}

\section{BACKGROUND}

The posterior half of the foot is made of seven tarsal bones. Talus is seen above calcaneus. It has a head, neck and body. There are three facets anterior, middle and posterior facets that articulate with corresponding facets of the calcaneus. The middle and posterior facets are separated by a groove sulcus tali. We wanted to know the morphometric measurements of talus in South Keralites in this study.

\section{METHODS}

The study was done on 68 dry human tali of unknown age and sex in the Department of Anatomy, Government medical college, Trivandrum. The measurements were taken i.e., length, width and height of talus using vernier calipers. The length, width and height of sulcus tali were also measured. The range and mean of measurements were estimated. The calcaneal facets were studied and classified to find the most common and least common types. Data analysis was performed using SPSS ver 16.0.

\section{RESULTS}

The mean anteroposterior length of the talus was $4.84 \pm 0.44 \mathrm{~cm}$. The mean transverse length was $3.46 \pm 0.47 \mathrm{~cm}$. The mean height of the talus was $2.56 \pm 0.31$ $\mathrm{cm}$. Anteroposterior length ranged from 3.84 to 6.07 . The transverse length of the talus ranged from $2.81-5 \mathrm{~cm}$. Height of talus ranged from $2-3.2 \mathrm{~cm}$. The mean anteroposterior length of sulcus tali was $2.09 \pm 0.45 \mathrm{~cm}$. The mean height of sulcus tali was $0.55 \pm 0.09 \mathrm{~cm}$. The mean width of sulcus tali was $0.62 \pm 0.30 \mathrm{~cm}$. Anteroposterior length of sulcus tali ranged from $1.4-3.8 \mathrm{~cm}$. The transverse length of sulcus tali ranged from 0.34 to $1.6 \mathrm{~cm}$. Height of sulcus tali ranged from 0.2 to 0.7 $\mathrm{cm}$, regarding the type of facets, type 2 was most common and type 4 was found to be absent.

\section{CONCLUSIONS}

The adequate knowledge of the anatomy of the talus is significant not only to the anatomists but also to the orthopaedic surgeons as fractures of the talus are quite common and lead to avascular necrosis, arthritis and when unrecognized, chronic pain and non-union 3. Talectomy has been described as a limb-saving procedure for the treatment of neglected talipes equinovarus deformity.

\section{KEY WORDS}

Talus, Sulcus Tali, Calcaneal Facet Morphometric Measurements of Talus in South Keralites.
Corresponding Author:

Dr. Leena Ammini Bhaskaran, Aswathy, Koora-40, Koottamvila Road, Vattiyoorkavu P. O.,

Thiruvananthapuram-13, Kerala, India.

E-mail: ableena@gmail.com

DOI: $10.14260 /$ jemds/2021/751

How to Cite This Article:

Bhaskaran LA, Sreedhar LSL. Morphometric measurements of talus in South Keralites. J Evolution Med Dent Sci 2021;10(43):3711-3714,

10.14260/jemds/2021/751

Submission 06-09-2021,

Peer Review 15-10-2021,

Acceptance 21-10-2021,

Published 25-10-2021.

Copyright (C) 2021 Leena Ammini Bhaskaran et al. This is an open access article distributed under Creative Commons Attribution License [Attribution 4.0 International (CC BY 4.0)] 


\section{BACKGROUND}

Talus (astragalus) is the second-largest tarsal bone of the seven without muscular and tendinous attachments. However, it plays an important role in transmitting body weight and in maintaining the medial longitudinal arch of the foot. It occupies the middle and upper part of the tarsus, supporting the tibia above, resting upon the calcaneus below, articulating on either side with the malleoli, and in front with the navicular. It consists of the body head and neck. The inferior surface of the body presents two articular areas, the posterior and middle calcaneal surfaces, separated from one another by a deep groove, the sulcus tali. The groove runs obliquely forward and lateralward, becoming gradually broader and deeper in front: in the articulated foot it lies above a similar groove upon the upper surface of the calcaneus, and forms together with a canal (sinus tarsi). The posterior calcaneal articular surface is large and of an oval or oblong form. ${ }^{1}$ It articulates with the corresponding facet on the upper surface of the calcaneus/ and is deeply concave in the direction of its long axis which runs forward and lateralward at an angle of about $45^{\circ}$ with the median plane of the body. The middle calcaneal articular surface is small, oval and slightly convex; it articulates with the upper surface of the sustentaculum tali of the calcaneus. The anterior articular surface is placed on the anterior part of the body and articulates with the anterior calcaneal facet on the talus. ${ }^{1}$ Classification given by Arora ${ }^{2}$ et al. Kaur ${ }^{3}$ et al. Garg ${ }^{4}$ et al. Chandra Philip 5 about the types of calcaneal facets were chosen for this study. Accordingly, there are 5 types of calcaneal articular facet on the talus and the fifth type is classified into 3 subtypes.

A k Arora ${ }^{2}$ et al. studied 500 North Indian tali and studied calcaneal facet of which type 2 was the highest with $78 \%$ and type 3 was least in number. Articular facets of talus and calcaneum were studied in 300 dry human tali by R Garg ${ }^{4}$ et al. in the population of Rajasthan. Type I was found in $39 \%$ of cases. Type II in $43.7 \%$ cases, Type III in $6 \%$ cases, Type IV in $5.3 \%$ cases and Type $\mathrm{V}$ was found in $6 \%$ cases; type $\mathrm{V}$ had two subtypes. Subtype 'A' was found in $5 \%$ of cases \& subtype 'B' was found in $1 \%$ of cases. Bhanu Sudha Parimala Namburu et al. ${ }^{6}$ studied 84 tali (40 right and 44 left) of unknown sex, obtained from the Department of Anatomy of N. R. I Medical College, Guntur. The mean length of the talus was $5.33 \mathrm{~cm}$; Mean width was $3.79 \mathrm{~cm}$ and mean height was $2.52 \mathrm{~cm}$ in the present study. The percentage of tali with type 1 facets was the highest (52\%). Type 3 was rarest. Fifty adult dry human tali from the Department of Anatomy, Nepalgunj Medical College Chisapani, Nepal were studied by Bilodi AK and Agrawal BK. ${ }^{7}$ They studied calcaneal facets and found that type 5 was the most common (56\%) and type 4 was absent. Vijay Laxmi and Nidhi Sharma ${ }^{8}$ studied 100 dry (50 right \& 50 left) adult tali of unknown age and sex obtained from the Department of Anatomy, Government Medical College, Amritsar. Type I facets were highest in incidences i.e., $45 \%$ and Type IV were lowest (5\%). Niladri Kumar Mahato, Sathya Narayana Murthy, ${ }^{9}$ SRM Medical College \& Research Centre, Kancheepuram studied the dimensions of 162 tali Mean length was $55.76 \mathrm{~mm}$ and mean width was $30.11 \mathrm{~mm}$. Manjunath V Motagi10 et al. studied 50 dry human tali of unknown age and sex of South Indian origin. They also studied the length and width of sulcus tali in addition to the dimensions of the talus. There was no statistical difference between the right and left sides. They also studied the angle of inclination and declination. Saif Omer $^{11}$ et al. studied 40 dry human tali and their morphometric measurements. They studied 20 pairs and concluded that the tali of either side are symmetrical. They studied Talar length (Tl), Talar width (Tw) and Talar height (Th) from forty intact dry adult tali. Their study was to throw some light on morphometry of talus bone in the state of Bihar. Articular facets of talus and calcaneum in the Anatolian population were studied by Nesshan Boyen ${ }^{12}$ et al. They also studied the dimensions of talus and sulcus tali. The mean length of the left tali was $50.5 \pm 3.81 \mathrm{~mm}$. The mean length of the right tali was $39.5 \pm 2.97 \mathrm{~mm}$. The width of the right and left tali was found to be $53.1 \pm 4.38 \mathrm{~mm}$ and $39.3 \pm 3.66 \mathrm{~mm}$, respectively. The average width, length and depth of left sulcus tali was $5.2 \pm 1.09 \mathrm{~mm}, 21.7 \pm 2.73 \mathrm{~mm}$ and $5.7 \pm 0.84 \mathrm{~mm}$, and that of right tali was $6.1 \pm 2.05 \mathrm{~mm}$, $21.1 \pm 3.66 \mathrm{~mm}$ and $5.7 \pm 1.52 \mathrm{~mm}$, respectively. Variations in talar anatomy can be of help for the reconstruction and rehabilitation of the foot. Measures of cranium, pelvis and long bones are used to evaluate population, gender and age. However, it may also be required to use other bones in the researches using bone pieces instead of the entire bone. ${ }^{10}$

\section{Objectives}

- To estimate mean and range of length, width and height of talus.

- To estimate the mean and range of width, length and depth of sulcus tali.

- To find out the most common and rarest type of calcaneal facets.

\section{METHODS}

This is a descriptive cross-sectional study done in the Department of Anatomy, Government medical college, Trivandrum from April 2021 to June 2021.

\section{Method}

The sample size was calculated using the formula

$\mathrm{n}=\frac{\left[Z_{1-\alpha / 2}^{2}\right] \times \sigma^{2}}{d^{2}}$

$\sigma=0.21$ (standard deviation of maximum length of talus was $0.21 \mathrm{~cm}$ in the study by Bhanu Sudha Parimala Namburu et al. ${ }^{6}$

$\mathrm{d}=$ absolute precision was taken as 0.05 .

$\frac{1-\alpha}{2}=$ desired confidence level taken as $95 \%$

The study was done on 68 dry human tali of unknown age and sex using vernier calipers and protractors. The measurements were taken i.e.-length, width and height of talus. The length, width and height of sulcus tali were also measured. The range and mean of measurements were 
estimated. The calcaneal facets were studied and classified to find the most common and the least common type.

1. Maximum anteroposterior length (L): is measured as the distance between the most anterior and posterior points of the talus.

2. Maximum transverse width (W): is the maximum distance between the most medial and most lateral points on the body of the talus.

3. Maximum vertical height $(\mathrm{H})$ : is the maximum distance between the most superior and inferior points on the body of the talus.

4. The width of the sulcus tali was taken as the distance between the anterior and posterior margins of the sulcus.

5. The length of the sulcus tali was taken as the distance between the medial and lateral margins of the sulcus.

6. The depth of the sulcus tali/ sulcus calcanei was taken as the distance between the margin and floor of the sulcus.

The classification given by Arora ${ }^{2}$ et al. of various types of calcaneal articular facets was followed in the present study-

1. Type I: Anterior and middle facets completely fused.

2. Type II: Anterior and middle facets are separated by a ridge.

3. Type III: Anterior and middle facets are separated partly by a ridge and partly by a groove.

4. Type IV: Anterior and middle facets are separated by a non-articular groove. In the above 4 types, a separate posterior calcaneal facet was present.

5. Type V: In this type middle facet fuses with the posterior facet. The subtypes a, b, c were classified based on the anterior facet.

Va- Anterior, middle and posterior facets completely fused resulting in a single continuous facet. $\mathrm{Vb}$ - Anterior facet completely separated by a groove from the combined middle and posterior facet. Vc- Anterior facet separated by a ridge from the combined middle and posterior facet.

The sample size was estimated to be 68 .

Specimens used for the study were obtained from collected repositories. 68 intact tali were taken for the study. Tali with anomaly and broken were excluded.

Data were entered in an excel sheet and statistical analysis was carried out by SPSS software version 2.0.

Categorical variables were expressed as frequencies and proportions and continuous variables were expressed as mean and standard deviation. Association between categorical variables was analysed by chi-square test. Comparison of quantitative variables between two groups was analysed by unpaired t-test. A $\mathrm{P}$ value $<0.05$ was considered statistically significant. Data analysis was performed using SPSS ver 16.0.

\section{RESULTS}

\begin{tabular}{|cccccc|}
\hline & N & \multicolumn{2}{c|}{ AP (cm) } & t & P \\
Right & 34 & 4.86 & 0.51 & & \\
Left & 34 & 4.82 & 0.36 & 0.229 & 0.686 \\
Total & $\mathbf{6 8}$ & $\mathbf{4 . 8 4}$ & $\mathbf{0 . 4 4}$ & & \\
\hline \multicolumn{7}{c}{ Anteroposterior Length } \\
\hline
\end{tabular}

\begin{tabular}{|c|c|c|c|c|c|}
\hline & \multirow{2}{*}{$\mathbf{N}$} & \multicolumn{2}{|c|}{ Transverse $(\mathrm{cm})$} & \multirow{2}{*}{$\mathbf{t}$} & \multirow{2}{*}{$\mathbf{P}$} \\
\hline & & Mean & SD & & \\
\hline Right & 34 & 3.37 & 0.44 & \multirow{3}{*}{0.084} & \multirow{3}{*}{0.172} \\
\hline Left & 34 & 3.56 & 0.50 & & \\
\hline Total & 68 & 3.46 & 0.47 & & \\
\hline
\end{tabular}

\begin{tabular}{|c|c|c|c|c|c|}
\hline & \multirow[b]{2}{*}{$\mathbf{N}$} & \multicolumn{2}{|c|}{ Height (cm) } & \multirow[t]{2}{*}{$\mathbf{t}$} & \multirow[t]{2}{*}{$\mathbf{P}$} \\
\hline & & Mean & SD & & \\
\hline Right & 34 & 2.53 & 0.29 & \multirow{3}{*}{0.102} & \multirow{3}{*}{0.493} \\
\hline Left & 34 & 2.59 & 0.32 & & \\
\hline Total & 68 & 2.56 & 0.31 & & \\
\hline \multicolumn{6}{|c|}{ The Mean Width was $3.46 \pm 0.47 \mathrm{~cm}$. P-Value was 0.172 Height } \\
\hline
\end{tabular}

\begin{tabular}{|c|c|c|c|c|c|c|}
\hline \multirow{2}{*}{ Type of Facet } & \multicolumn{2}{|c|}{ Right } & \multicolumn{2}{|c|}{ Left } & \multicolumn{2}{|c|}{ Total } \\
\hline & $\mathbf{N}$ & $\%$ & $\mathbf{N}$ & $\%$ & $\mathbf{N}$ & $\%$ \\
\hline 1 & 12 & 35.3 & 1 & 2.9 & 13 & 19.1 \\
\hline 2 & 16 & 47.1 & 27 & 79.4 & 43 & 63.2 \\
\hline 3 & 4 & 11.8 & 6 & 17.6 & 10 & 14.7 \\
\hline 5 & 2 & 5.9 & 0 & 0 & 2 & 2.9 \\
\hline Total & 34 & 100 & 34 & 100 & 68 & 100 \\
\hline \multicolumn{7}{|c|}{ Type of Facet } \\
\hline
\end{tabular}

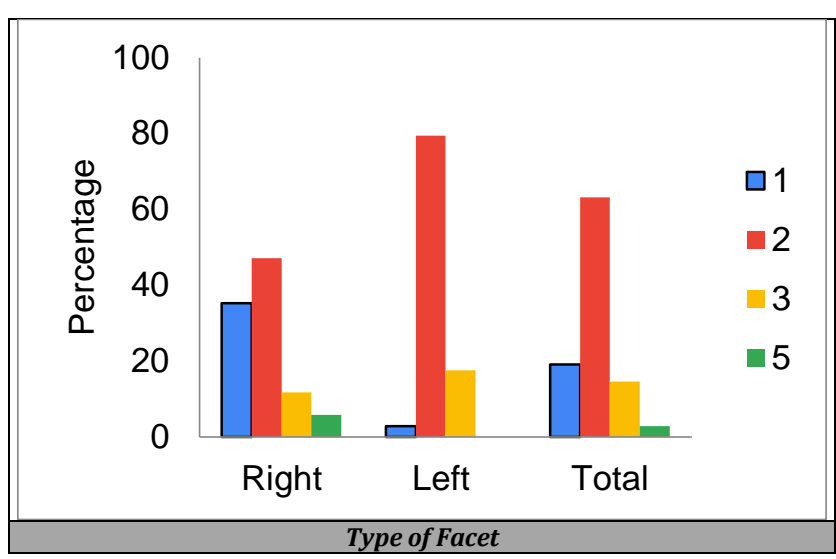

\section{DISCUSSION}

The mean anteroposterior length of the talus was $4.84 \pm 0.44$ $\mathrm{cm}$. The mean transverse length/width was $3.46 \pm 0.47 \mathrm{~cm}$. The mean height of the talus was $2.56 \pm 0.31 \mathrm{~cm}$. Anteroposterior length of talus ranged from 3.84 to 6.07. The transverse length of the talus ranged from $2.81-5 \mathrm{~cm}$. Height of talus ranged from $2-3.2 \mathrm{~cm}$.

The mean anteroposterior length of sulcus tali was $2.09 \pm$ $0.45 \mathrm{~cm}$. The mean height of sulcus tali was $0.55 \pm 0.09 \mathrm{~cm}$. The mean width of sulcus tali was $0.62 \pm 0.30 \mathrm{~cm}$. Anteroposterior length of sulcus tali ranged from $1.4-3.8 \mathrm{~cm}$. The transverse length of sulcus tali ranged from 0.34 to 1.6 $\mathrm{cm}$. The height of sulcus tali ranged from 0.2 to $0.7 \mathrm{~cm}$.

\begin{tabular}{|c|c|c|c|c|c|c|}
\hline Parameter & $\begin{array}{l}\text { Ari }{ }^{13} \\
\text { et al. }\end{array}$ & $\begin{array}{c}\text { Gautam }^{14} \\
\text { et al. }\end{array}$ & $\begin{array}{c}{ }^{4} \text { Saif omer }{ }^{11} \\
\text { et al. }\end{array}$ & $\begin{array}{l}\text { Motagi }{ }^{10} \\
\text { et al. }\end{array}$ & $\begin{array}{c}\text { Bhanu }^{6} \\
\text { et al. }\end{array}$ & $\begin{array}{c}\text { Present } \\
\text { study }\end{array}$ \\
\hline $\begin{array}{l}\text { Mean Length } \\
\text { (rt) }\end{array}$ & 5.72 & 5.23 & 5.31 & 5.42 & 5.37 & 4.86 \\
\hline $\begin{array}{l}\text { Mean Length } \\
\text { (lt) }\end{array}$ & 5.64 & 5.29 & 5.31 & 5.33 & 5.34 & 4.82 \\
\hline $\begin{array}{c}\text { Mean } \\
\text { Width(rt) }\end{array}$ & 4.91 & 3.79 & 4.02 & 3.62 & 3.79 & 3.37 \\
\hline $\begin{array}{c}\text { Mean } \\
\text { Width(lt) }\end{array}$ & 4.69 & 3.68 & 4.02 & 3.77 & 3.8 & 3.56 \\
\hline Mean Ht (rt) & & & 2.93 & & 2.51 & 2.53 \\
\hline Mean HT (lt) & & & 2.93 & & 3 & 2.59 \\
\hline
\end{tabular}


The type of calcaneal facet most commonly observed was Type $2(63.2 \%)$ which agrees with the study by Arora $^{2}$ et al. Bilodi ${ }^{7}$ et al. and Rohin Garg. ${ }^{4}$ Type 5 was the least commonly observed type (2.9\%) which was seen in $2 \%$ in a study by Arora $^{2}$ et al. But the least common type seen in Arora ${ }^{2}$ et al. was Type 3. Only one left talus had Type 1 facet whereas 12 right tali had Type 1 facet. Type 5 was subclassified into $a, b$ and c. Only two right tali showed type 5 , subtypes being a for both with a fusion of all 3 facets.

\begin{tabular}{|c|c|c|c|c|c|c|c|}
\hline $\begin{array}{l}\text { Sl. } \\
\text { No. }\end{array}$ & Study & Place & $\begin{array}{c}\text { Type } 1 \\
(\%)\end{array}$ & $\begin{array}{c}\text { Type } 2 \\
(\%)\end{array}$ & $\begin{array}{c}\text { Type } 3 \\
(\%)\end{array}$ & $\begin{array}{c}\text { Type } 4 \\
(\%)\end{array}$ & $\begin{array}{c}\text { Type } 5 \\
(\%)\end{array}$ \\
\hline 1 & Arora $^{2}$ et al. & North India & 16 & 78 & 1 & 3 & 2 \\
\hline 2 & Kaur et al. ${ }^{3}$ & North India & 45 & 24 & 9 & 5 & 17 \\
\hline 3 & Rohin Garg ${ }^{4}$ & Rajasthan & 39 & 43.7 & 6 & 5.3 & 6 \\
\hline 4 & $\begin{array}{l}\text { Bhanu Sudha } \\
\text { et al. }{ }^{6}\end{array}$ & $\begin{array}{l}\text { Andhra } \\
\text { Pradesh }\end{array}$ & 52 & 32 & 1 & 3.6 & 10.7 \\
\hline 5 & Bilodi $^{7}$ et al. & Nepal & 10 & 50 & 16 & 5 & 18.4 \\
\hline 6 & Present study & South Kerala & 19.2 & 63.2 & 14.7 & 0 & 2.9 \\
\hline
\end{tabular}

Type 4 facets that were observed in the study by Arora $^{2}$ et al. Kaur ${ }^{3}$ et al. Rohin Garg ${ }^{4}$, Bhanu ${ }^{6}$ et al. Bilodi ${ }^{7}$ et al. were not observed in the present study. Type 3 facets which were 1 percent in the study by Arora ${ }^{2}$ et al. Bhanusudha ${ }^{6}$ et al. were noticed in $14.7 \%$ in the present study.

In the study by 0 mer $^{11}$ et al. length of the talus was 5.31 $\mathrm{cm}$, the width was $4.02 \mathrm{~cm}$, height was $2.93 \mathrm{~cm}$, the width, length and depth of left and right sulcus tali were: $5.2 \pm 1.09$ $\mathrm{mm}, 21.7 \pm 2.73 \mathrm{~mm}, 5.7 \pm 0.84 \mathrm{~mm}$; and $6.1 \pm 2.05 \mathrm{~mm}, 21.1$ $\pm 3.66 \mathrm{~mm}, 5.7 \pm 1.52 \mathrm{~mm}$, respectively in a study by Neshhan Boyen ${ }^{12}$ et al. Right sulcus tali measured $2.38 \pm 0.40$ in length, $2.38 \pm 0.40$ and $0.52 \pm 0.10 \mathrm{~cm}$ in width and depth respectively in the present study which was less compared to the study by Neshhan. ${ }^{12}$ Left sulcus tali measured $1.81 \pm 0.28$ long, $0.67 \pm 0.34 \mathrm{~cm}$ wide, $0.57 \pm 0.08 \mathrm{~cm}$ deep in the present study which was less compared to the study of talus in the Anatolian population.

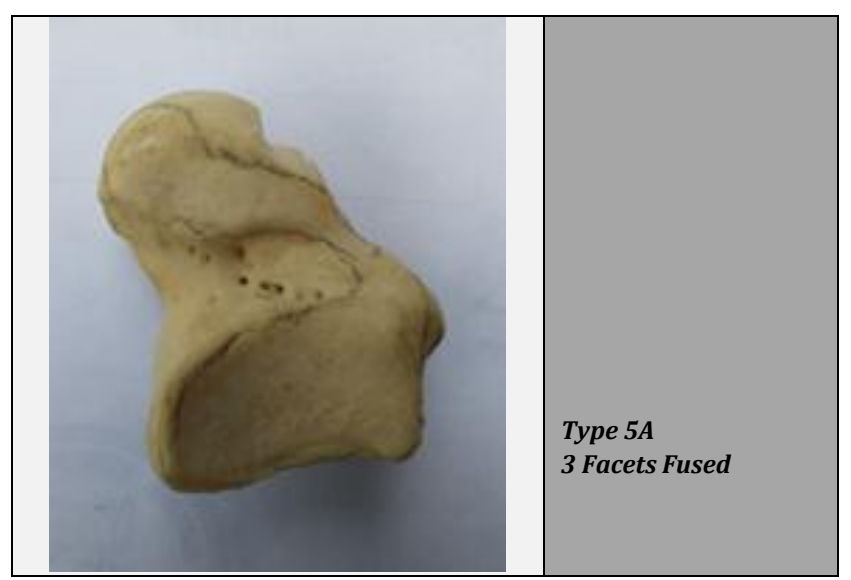

\section{CONCLUSIONS}

The dimensions of the talus are important for surgeons while doing talectomy and while fixing artificial prostheses. Dimensions are not significantly different between both sides according to this study. However, the occurrence of the type of facet differs and may be related to the type/geography of the place where they reside. So slight change in morphology is observed among people from different regions. Since the talus is an important weight-bearing bone, the stress patterns may cause a difference in its morphology. The findings can be used to find out the race of unidentified bones as well.

Data sharing statement provided by the authors is available with the full text of this article at jemds.com.

Financial or other competing interests: None.

Disclosure forms provided by the authors are available with the full text of this article at jemds.com.

\section{REFERENCES}

[1] Gray H, Lewis WH. Anatomy of the human body. Philadelphia : Lea \& Febiger 1918: p. 268.

[2] Arora AK. Gupta SC, Gupta CD, et al. Variations in calcaneal articular facets in Indian Tali. Anat Anz 1979;146(4):377-80.

[3] Kaur M, Kalsey G, Laxmi V. Morphological classification of tali on the basis of calcanean articular facets. PB J Orthop 2011;12(1):57-60.

[4] Garg R, Babuta S, Mogra K, et al. Study of variations in pattern of calcaneal articular facets in human tali in the population of Rajasthan (India). People's Journal of Scientific Research 2013;6(2):18-23.

[5] Philip XC, Prabavathy G. Study of anatomical variations of human tali based on their calcaneal articular facets. Research Journal of Pharmaceutical, Biological and Chemical Sciences 2014;5(5):1484-90.

[6] Namburu BSP, Kaavya H, Reddy SM, et al. A study of morphology of talus and its calcaneal facets. Int J Anat Res 2017;5(4.2):4570-74.

[7] Bilodi AK, Agarwal BK. Study of fifty human tali for calcaneal articular facets. Kathmandu Univ Med J 2003;2(7):213-5.

[8] Laxmi V, Sharma N. Morphological classification of tali on the basis of calcanean articular facets-a cadaveric study in north Indian population. IJSR 2017;6(4)1160-2.

[9] Mahato NK, Murthy SN. Articular and angular dimensions of the talus: inter-relationship and biomechanical significance. Foot (Edinb) 2012;22(2):859.

[10] Motagi MV, Kottapurath SR, Dharwadkar K. Morphometric analyses of human dry tali of South Indian origin. Int J Med Sci Public Health 2015;4(2):237-40.

[11] Omar S, Alam M, Gupta RB, et al. Bilateral symmetry of the talus: a study on 40 dry adult tali in Bihar. Int J Recent Sci Res 2015:6(4):3404-5.

[12] Boyan N, Ozsahin E, Kizilkanat E, et al. Morphometric measurement and types of articular facets on the talus and calcaneus in Anatolian population. Int J Morphol 2016;34(4):1378-85.

[13] Ari I, Kafa IM. Bone length estimation and populationspecific features of calcaneus and talus bones of the late byzantine era. Coll Antropol 2009;33(2):613-18.

[14] Gautham K, Clarista MQ, Sheela N, et al. Morphometric analysis of the human tali. CIBTech J Surg 2013;2(2):648. 